\title{
Whose Knowledge?
}

\section{Epistemic Injustice and Challenges in Attending to Children's Voices}

\author{
Guro Parr Klyve ${ }^{1 *}$ \\ 1 The Grieg Academy - Department of Music, University of Bergen \\ *guro.klyve@uib.no \\ Received: 31 March 2019 Accepted: 8 October 2019 Published: 1 November 2019 \\ Editors: Candice Bain, Maevon Gumble Reviewer: Susan Hadley
}

\begin{abstract}
In this essay, I will discuss the importance of having an awareness about epistemic justice, epistemic ignorance and epistemic injustice, and why this awareness is important in connection to children and patients in mental health care. I also suggest ways to avoid epistemic injustice when working with, and doing research with, children in mental health care. In doing so, I tie this to feminist epistemology where conceptions such as knowledge, knowers and objectivity are questioned, and dominant conceptions and practices of knowledge production are perceived as a systematic disadvantage of women and other subordinated groups (Anderson, 2017). I am as well linking this to queer epistemology which differs from feminist standpoint epistemology in the idea of the identity being "a point of departure for shared consciousness" (Hall, 2017, p. 163).
\end{abstract}

Keywords: epistemic injustice, children, mental health, feminist perspective, queer perspective

\section{Introduction}

Drawing on both queer theory and feminist theory in this essay, I will explore epistemic injustice and the challenges faced when attending to children's voices in mental health care.

Philosopher and feminist, Miranda Fricker (2007), defined "epistemic injustice" as "a wrong done to someone specifically in their capacity as a knower" (p. 1). Informed by this understanding, I am discussing how both children and patients in mental health care have been subjected to epistemic injustice, and how children in mental health care in this sense might experience a double epistemic injustice.

What are the challenges when considering epistemic justice in interviewing children in mental health care?

Fricker`s (2007) perspectives on epistemic injustice and ignorance are framed in a feministic epistemology. Discussions about objectivity in feminist epistemology are concerned with "limited location and situated knowledge" (Haraway, 1988, p. 583) 
and focused on how the knowers` social location affects "what and how she[/he/they] ${ }^{1}$ knows" (Anderson, 2017). In relation to these discussions, Fricker (2007) argues that people should be conceived "as operating as social types who stand in relations of power to one another" (p. 3).

In queer epistemology, one is instead focusing on an affectively attuned knowing, "a sensibility of something other than shared understanding" (Hall, 2017, p. 163). Queer theorists acknowledge other forms of epistemic injustices, such as epistemic violence (Hall, 2017) and "willful hermeneutical ignorance" (Pohlhaus, 2012), focusing on "the dialectical relation between interdependence and situatedness" (p. 720).

I perceive both feminism and queer theory as part of a broad discourse on gender. Through a discussion on epistemic injustice and ignorance, I will connect these two perspectives, focusing on two identity markers which seldom are discussed in the intersectionality debate on gender, namely children and patients in mental health care.

I am currently working on a Ph.D. project where the purpose is to gain more knowledge about how children experience music therapy during hospital admission in mental health care. The project is a qualitative study, and the problem statement is explored through a multiple case study design with 8 cases. I am conducting separate interviews with the children, as well as their parents, and several of the staff at the hospital will participate in focus group interviews. What is explored in this essay will be of importance when arguing for interviewing children in mental health care despite the challenges and critical issues this might imply (Einarsdóttir, 2007). It will also be important in interpreting and understanding the children's voices.

Even though my focus in this text is on children in mental health care, I do think there are examples that will be transferable to other identity markers.

\section{The child as a social competent actor}

What is a child? When working and doing research with children, this is an important question to ask. One could argue that it is an easy question to answer, emphasising age and development. It is, however, as much a question about how we (adults) perceive children, what their role and impact are in our society. All interaction with others is "predicated on the categories in which we spontaneously place them" (Gilbert, 2009, p. 93), and the binary opposition child/adult places children linguistically less valued than adults and dependent on them. Fixed categories, such as children and adults, gender and sex, are strongly criticized and questioned in queer theory, and binary oppositions such as feminine/masculine, woman/man, female/male are under constant deconstruction (Butler, 2006).

The "otherness" of children "somehow represents the very things which make children children" (Jones, 2001, p. 173). How we perceive this "otherness" and deal with it is a key issue in the relations between adulthood and childhood, as well as in research related to childhood. From an adult's position, the child seems to be more "other" the younger they are, Jones suggested, acknowledging how the inner worlds of young children are mysterious and distant to adults. At the same time, Jones referred to the infant research conducted by the biologist Trevarthen (1993), among others, which showed infants` capabilities for emotionality and communicating. This "communicative musicality" (Trevarthen \& Malloch, 2000) provides a basis for mutual understanding between people.

To communicate about "children" as a fixed category and a unified group of people might, however, simplify the complexity of the group. There is, nevertheless, something that apparently forms them as a group, including their youngness, newness, and "lack of accumulative experience and knowledge which make adults adults" (Jones, 2001, p. 175). This implies that children are defined as the binary opposite, the negative of adult, but, as Jones emphasises, it is important to realise that children "are not less than adult; they are different to adults" (p. 175, emphasis in original).

The children`s rights, defined by the UN Child Convention (UN, 2006), and a growing influence of the consumer have had a great influence on how childhood is viewed 
in society. What has changed has been an increasing understanding of the child as a competent social actor and children`s involvement in research (Powell \& Smith, 2009; Sinclair, 2004). Children are now not merely objects of inquiry but can be active participants in the research process. This development demands specific attention and capabilities in the researcher, as their methodological and ethical choices impact children`s participation in research (Powell \& Smith, 2009). Given the diversity of contexts and research problems, a child-centred perspective is suggested (Grover, 2004).

\section{Epistemic injustice}

Two of our most basic everyday epistemic practices are "conveying knowledge to others by telling them" and "making sense of our own social experiences" (Fricker, 2007, p. 1). Fricker brought to light certain ethical aspects of these practices by defining a distinctively epistemic kind of injustice, dividing it into two forms: testimonial injustice and hermeneutical injustice. In both, it is the subject that "suffers from one or another sort of prejudice against them qua social type" (p. 155). In testimonial injustice, "a hearer wrongs a speaker in his[/her/their] capacity as a giver of knowledge, as an informant" (p. 5), while in hermeneutical injustice it is "some significant area of one's social experience" that is "obscured from collective understanding owing to a structural identity prejudice in the collective hermeneutical resource" (p. 155).

\section{Testimonial injustice}

When the speaker is wronged in their capacity as a subject of knowledge, they are wronged in a capacity which is essential to human value (Fricker, 2007). This is a matter of credibility deficit, where someone receives lower credibility than they deserve. Fricker argued that various degrees of this happen all the time, referring to Shklar (1990) who pointed at injustice as something that is not a surprising abnormality, but rather a normal social baseline.

Social power is central in testimonial injustice, especially the particular kind of social power called identity power. Identity power is at work where there is an operation of power depending upon "shared imaginative conceptions of social identity" (Fricker, 2007, p. 14), and one example of this is gender. For example, gender identity power is active when a cis man influences a cis woman's action by making use of the identity as a cis man. One of Fricker's main example was from Minghella`s (2000) movie, The Talented Mr. Ripley, where Herbert Greenleaf wrongs Marge Sherwood's capacity as a knower in relation to the disappearance of their fiancé, Dickie Greenleaf. Marge is convinced (rightly) that Dickie's friend, Tom Ripley, has killed Dickie, but Herbert Greenleaf disregards Marge`s beliefs. "Marge, there's female intuition, and then there are facts" (Minghella, 2000, in Fricker, 2007, p. 88). Herbert Greenleaf thus fails to see Marge as a source of knowledge, and one might claim that there is a clear identity prejudice at work in this situation.

The primary harm of testimonial injustice is about exclusion from knowledge owing to "identity prejudice on the part of the hearer" (Fricker, 2007 p. 162). Identity prejudice is related to social identity, and the influence of this prejudice in the credibility judgement of a hearer is an "operation of identity power" (p. 28). Identity power can control our actions even despite our beliefs, as it is at "the level of the collective social imagination" (p. 15). Our responses to the testimony of others are learned through epistemic socialization and "our normal unreflective reception of what people tell us is conditioned by a great range of collateral experience" (Fricker, 2003, p. 161).

\section{Hermeneutical injustice}

The primary harm of hermeneutical injustice is about exclusion from knowledge owing to "structural identity prejudice in the collective hermeneutical resource" (Fricker, 2007, p. 162). This harm is in deep connection with the primary harm of testimonial injustice, but, according to Fricker, in hermeneutical injustice and in contrast to tes- 
timonial injustice, there is no culprit ? it is purely structural. Hermeneutical injustice happens when an individual is unable to understand their own experience because of a cognitive disadvantage stemming from a "gap in collective hermeneutical resources" (p. 6).

Fricker (2007) exemplified hermeneutical injustice with the story of Carmita Wood, a woman in the late 1960s, who experienced sexual harassment at the workplace. At that time, there were no words in the hermeneutical resources that could explain what happened, to neither Wood nor the male professor at work who sexually approached Wood. Wood developed chronic back pain and quit their job. Applying for unemployment insurance, Wood had a hard time explaining what had happened, and their application was denied. Wood joined a feminist group discovering that everyone in the group had had similar experiences, and they started to speak out about this "sexual intimidation," and "sexual coercion" (Brownmiller, 1990, in Fricker, 2007, p. 150), coming up with the word "sexual harassment."

When some groups are excluded from practices where social meaning is generated, "collective hermeneutical resources" (p. 6) inadequate to the experiences of marginalized social groups are produced. Collective impoverishment becomes unjustly and particularly disadvantageous to some groups of people, but not others, in concrete social situations, such as in the example of Carmita Wood. Hence, according to Fricker (2007), hermeneutical injustice is fundamentally "a kind of structural discrimination" (p. 161).

\section{Epistemic violence, epistemic ignorance and willful hermeneutic ignorance}

Queer epistemology brings another form of testimonial injustice into focus, namely "the epistemic violence" (Hall, 2017, p. 158) of mandatory testimony about one`s gender and sexuality. Testimonial injustice in queer epistemology is thus not only about the silencing of those who are marginally situated, but also about the epistemic violence maintained by the pressure to inhabit an identity category, "to understand oneself as a certain kind of person because of one's desires and actions" (p. 159).

Mason (2011) was critical of Fricker's central argument of hermeneutical injustice, claiming that Fricker`s analysis might contribute to the disempowerment and marginalization of non-dominant subjects. Mason argued that Fricker failed to see the possibility that subjects in marginalized groups might possess "non-dominant interpretive resources from which they can draw to understand and describe their experiences" (p. 295). According to Mason, marginalized subjects will hence not necessarily experience hermeneutical injustice, and even though Fricker (2007) emphasized that hermeneutical injustice is "not a subjective failing" (p. 169), I do, to a certain degree, agree with Mason. For instance, in Wood's example, Mason argued that the women understood that their experiences of sexual harassment were wrong even though they didn't have any name for it. It is not the socially recognized name that prevents groups from understanding. Mason (2011) suggested an "alternative kind of unknowing" (p. 298), which is at play when hermeneutical resources are insufficient with the experiences of someone in the community. This is hermeneutical injustice and "epistemically and ethically blameworthy ignorance" (p. 301). Mason here referred to Mills (1997) who focused on ignorance rather than knowledge, reflecting on how those with power can fail to understand, rather than marginalized groups, due to "epistemically irresponsible and ethically reprehensible practices of misinterpretation, misrepresentation evasion, and self-deception" (p. 303). In the context of epistemic ignorance, the comprehensibility of marginalized groups to dominant groups is prevented by "epistemic practices infected by ignorance, not by their own inability to understand their experiences" (Mason, 2011, p. 304).

Following up on Mills notion of epistemic ignorance, Pohlhaus (2012) paid attention to the relationship between interdependence and situatedness as an account of how it is possible to actively maintain such systemic ignorance. Pohlhaus critiqued 
Fricker (2007) and the limitations of hermeneutical injustice, pointing to the argument regarding willful hermeneutical ignorance. Marginally situated knowers may be epistemically disadvantaged, Pohlhaus (2012) argued, but those who are dominantly situated are also situated to know that their dominant epistemic resources are not very suitable in whole parts of the world. Willful hermeneutic ignorance describes how marginally situated knowers resist epistemic dominance actively through interacting with other marginally situated groups. At the same time, dominantly situated knowers continue to misinterpret and misunderstand the world. A dominantly situated group may maintain their ignorance "by refusing to recognize and by actively undermining any newly generated epistemic resource that attends to those parts of the world that they are vested in ignoring" (p. 728). One way this kind of ignorance appears might be through the maintenance of binary pronouns. I find these perspectives both relevant and interesting, and I will discuss them further in relation to children.

\section{Epistemic injustice and children}

Considering my above discussion of children`s "otherness" in society, prejudices against children and childhood are clearly present. The epistemic prejudices are related to the prejudices and assumptions adults have, implicitly and explicitly, about children (Murris, 2013). Do these prejudices make children more vulnerable to epistemic injustice (Carela \& Györffyb, 2014)? Fricker (2007) claimed that "wherever there are identity prejudices in the discursive environment, there is a risk of testimonial injustice" (p. 86). Identity prejudice, which is produced by binary discourses, operates as a "widely held disparaging association between a social group and one or more attributes" (p. 35), and talking about children as a fixed category might emphasize prejudices in this context. As earlier mentioned, it might be insufficient, and also wrong, to talk about children as a fixed category, and I argue that it also underpins children`s vulnerability to epistemic injustice.

Carela and Györffyb (2014) claimed that the question of epistemic injustice in relation to children is of particular importance in health care. This is because children have important information about their own well-being, and Carela and Györffyb emphasized how one can easily disregard what children actually tell us. Murris (2013) acknowledged this as well, proposing that "hearers' prejudices cause adults to miss out on knowledge offered by the child, but not heard by the adult" (p. 246). Despite these important perspectives on children 's prone position in relation to epistemic injustice, the literature is remarkably silent on children in this context, and it is further silent on what influences adults when hearing children`s voices and what we regard as "real" knowledge (Murris, 2013). "Queer listening" (Bonenfant, 2010; Hadley \& Gumble, 2019), which involves "developing a certain virtuosity" (Bonenfant, 2010, p. 78) might be one way for adults to hear the knowledge offered by the child, and I will consider this further when examining different virtues for epistemic injustice.

In relation to hermeneutical injustice, I argue that children often experience exclusion from meaning making. This might create a "gap in collective hermeneutical resources" (Fricker, 2007, p. 6), and thus possibly prevent children from making sense of their own social experiences. In some social contexts, hermeneutical injustice happens when someone is "socially constituted as something they are not" (p. 168). Fricker exemplifies this with Edmund White`s (1983) book A Boy`s Own Story, where a boy growing up in 1950s America has a strong sense of dissonance around their own feelings for other men and the authoritative hermeneutical constructions of the social identity of being gay. The boy`s young self is, in this context, formed through all of these different constructions about homosexuality around them, exemplifying how some might thus "be prevented from becoming who they are" (Fricker, 2007, p. 168). Connecting this with queer epistemology and the previously mentioned mandatory testimony of one`s gender and sexuality, hermeneutical injustice might also contain epistemic violence.

I understand hermeneutical constructions as the primary harm of hermeneutical injustice in relation to children, as well as the epistemic violence that occurs when facing 
pressure to inhabit an identity category. Considering the different aspects that predispose children to epistemic injustice, it is crucial to find ways to prevent epistemic injustice when working and doing research with children.

\section{Epistemic injustice and patients in mental health care}

One might also ask, is epistemic injustice relevant when communicating about patients in mental health care? I argue that it certainly is, considering the many identity prejudices against patients in mental health care that are clearly present in society (Johnstone, 2001). Central to mental health legislation, "some people lack the capacity to make decisions" (Lakeman, 2010, p. 151). The implication of this is that the words, preferences, and choices of "some people" (i.e., patients in mental health care) and their interpretations of their problems, "lack coherence, logic or credibility" (p. 151). Considering how Fricker (2007) identified the primary harm of testimonial injustice, patients in mental health care seem to be vulnerable to testimonial injustice. Lakeman (2010) argued that testimonial injustice is foundational for other forms of injustice, such as social and procedural justice, exemplifying how decisions in mental health services are based on assessment of the credibility of the person`s testimony.

Patients in mental health care might also experience hermeneutical injustice in that they might be deprived of their means of understanding and communicating their own social experience (Wardrope, 2015). This is central to the critique of medicalization. Wardrope (2015) claimed that "medicine`s epistemic authority eclipses all other understandings in our collective hermeneutical resources" (p. 342). Patients in these concrete social situations might suffer an unjust disadvantage and hence a sort of "structural discrimination" (Fricker, 2007, p. 161). Wardrope, however, does not agree with the critique of medicalization, referring to the risk of committing the other kind of epistemic injustice, testimonial injustice. Wardrope (2015), here referred to how the critiques ascribe insufficient credibility to the testimonies of, for instance, children with ADHD diagnosis, where the majority of the children who were asked "rejected the medicalization critique`s analysis" (p. 348).

The main disabling barrier in mental health care is considered to be social stigma (Beresford, Nettle, \& Perring, 2010; Rolvsjord, 2014). An epistemically and ethically blameworthy ignorance might occur where lesbian, gay, bisexual, transgender, and queer (LGBTQ) individuals in mental health care experience pervasive stigma in mental health care (Bain et al., 2016; Hadley \& Gumble, 2019). This stigma might affect how LGBTQ individuals are heard as mental health patients and willful hermeneutical ignorance (Pohlhaus, 2012) happens.

\section{The virtue of epistemic justice}

Fricker (2007) suggested different virtues for the two different kinds of epistemic injustice. In order to avoid testimonial injustice, Fricker claimed that the hearer has to have a "corrective anti-prejudicial virtue that is distinctively reflexive in structure" (p. 91). The ideal is to neutralize impacts of prejudices, and one should overcompensate to increase the level of credibility that would have been there without prejudices. "The virtuous hearer neutralizes the impact of prejudice in her[/his/their] credibility judgements" (p. 92) Fricker claimed. The virtue of hermeneutical justice is also corrective in structure, and it involves a more "socially aware kind of listening" (p. 171). In order to avoid hermeneutical injustice, one has to possess a sensitivity or alertness to the possibility that our interlocutors' difficulties in trying to make something intelligible in the communication is not because they're not intelligent, but rather because there is a gap in collective hermeneutical resources. One has to realize that the speaker might struggle with an "objective difficulty, and not a subjective failing" (p. 169). Fricker, however, does not meet Mason`s (2011) nor Pohlhaus' (2012) critique in these virtues, failing to recognize the non-dominant interpretive resources which subjects in marginalized groups might possess, as well as the willful hermeneutic ignorance in dominant situated groups. 
The previous mentioned "queer listener" (Bonenfant, 2010) might be related to Fricker's term the "virtuous hearer" (2007). Bonenfant (2010) suggested that the voice is a "form of social touch" (p. 77) and that this touch can "activate reactions in bodies, literally, by vibrating them" (p. 77). "Queer is a doing, not a being" (p. 78), and the queer listener "listens out for, reaches toward, the disoriented or differently oriented other" (p. 78), as well as finding appreciation of the other. Connecting this to music therapy, Hadley and Gumble (2019) claimed that when engaging in queer listening, "music therapy can be transformed into a space" (p. 226) where this appreciation can happen. As Fricker (2007) was also emphasizing, when "listening out for queer desires and needs" (Bonenfant, 2010, p. 78) a sensitivity is required.

\section{Hearing the competent and credible child and embracing epistemic humility}

As I have advocated earlier, children and patients in mental health care seem to be vulnerable to epistemic injustice. In my Ph.D. project, the children who are participants in the study are both "children" and "patients in mental health care." What kind of precaution is needed in order to avoid epistemic injustice in this context?

Exclusion from knowledge is, as earlier mentioned, the primary harm of testimonial injustice, and one might also argue that this is the primary harm in research. According to Fricker (2007), prejudices can shape our credibility judgements despite our own beliefs, and testimonial injustice thus might happen without us being aware of it. To avoid the injustice, then, the hearer has to be critically aware and identify the impact of identity power in their credibility judgement. The hearer has to be alert not only to the speaker's social identity, but also to the impact of their own social identity on their credibility judgement. Being reflexive and critically aware to how we perceive "children" and "patients in mental health care" is hence a key issue to avoiding testimonial injustice in the interaction with those children in mental health care that are participating in this study, as well as how we perceive ourselves ("adults"/"researchers") in this context. Another important aspect is a critical awareness regarding the difference as structured discursively in the binary oppositions between "children" and "adults" and "researchers" and "patients in mental health care." There is further importance to how this might impact relationships, and thus the interaction, between the researcher and the children participating in the study. The "otherness" of the fixed categories of children and of patients in mental health care, and the prejudices one might have connected to this "otherness", implicit or explicit, are crucial and important to interrogate and be aware of in efforts of avoiding testimonial injustice in the research process.

Fricker (2007) argued that a more socially aware kind of listening, as in the virtue of hermeneutical justice, involves "listening as much to what is not said, as to what is said" (p. 171-172). When searching for these other voices, the queer listener has to possess a virtuosity and a "certain kind of attunement to hearing beyond syntax" (Bonenfant, 2010, p. 78). Listening to what is not said is particularly interesting in relation to children, considering, for instance, the previously suggested child-centred perspective and the plentiful advice for implementing varied techniques when interviewing children (Einarsdóttir, 2007). Children often communicate and express themselves through different modalities and not just through words. As earlier mentioned, even infants communicate and actively take part in communication through an inborn "communicative musicality" (Trevarthen \& Malloch, 2000), and the knowledge about this non-verbal communication gives us an idea about what adults might miss if they ignore what is not said. Important information and relational initiatives from children can be missed, resulting in an exclusion of children`s knowledge and ways of expressing themselves from hermeneutical resources. Hermeneutical injustice seems to affect children more strongly than other groups, and to avoid this injustice requires, according to Fricker (2007), a reflexive and critical awareness, but also, I argue, a more general analysis of structurally embedded power in the different social situations. 
If we consider this alongside the work of Mason (2011), the case of hermeneutical injustice might also relate to another kind of unknowing, which is not a hermeneutical injustice but rather an epistemically and ethically blameworthy ignorance. Children might possess "non-dominant interpretive resources" (p. 295) which can be used to "understand and describe their experiences" (p. 295), and according to Mills (1997), it is not always the marginalized that fails to understand their experiences but, just as often those in power, those in the dominant group. Pohlhaus (2012) argued that hermeneutical injustice, as Fricker (2007) has defined it, happens when "a marginally situated knower has no community with which to develop adequate epistemic resources" (Pohlhaus (2012, p. 731) to make sense of their own experiences. However, willful hermeneutical ignorance occurs where marginally situated knowers have a community where adequate epistemic resources are developed, but dominantly situated knowers do not want to acquire this knowledge.

If adults then systematically ignore what children communicate, what implications might this have in research? Will it, in light of this question, even be possible for adults to understand what children communicate about their experiences?

When our interlocutors have difficulties in trying to make something intelligible in communication, Fricker (2007) emphasizes that it is not because the interlocutor is not intelligent but rather because there is a gap in collective hermeneutical resources. Because of this gap, we have to possess a sensitivity or alertness to this possibility. But is this sensitivity and alertness enough? Do we have the right tools in our epistemic capacities to go beyond the gaps developed through a systemic ignorance of children`s different experiences and expressions? Wardrope (2015) critiques Fricker`s suggestion to not engage with "the root causes of epistemic injustice" (p. 350). Wardrope`s (2015) alternative is "epistemic humility" (p. 350), an awareness of one`s own epistemic capacities and the limitations of these, as well as an active searching for contrasting and complementary perspectives outside oneself to go beyond these shortcomings. Wardrope argued that it is important to not just involve personal awareness but also to involve public expressions of the epistemic limitations one has. This might be a useful perspective to bring into research with children and patients in mental health care.

\section{Conclusion}

Who has the right to knowledge? And whose knowledge are we seeking? Doing research with children in mental health care involves many different challenges. One of these includes the risk of epistemic injustice, and this risk is a central issue within this specific context. Children and patients in mental health care seem to be vulnerable to epistemic injustice - both testimonial and hermeneutical injustice, as well as willful hermeneutical ignorance. In order to avoid this, it is of special importance to be critically and reflexively aware of the prejudices one might have as a researcher towards the fixed categories of "children" and "patients in mental health care" and also to deconstruct binary oppositions in an attempt to disrupt identity prejudices. It is also crucial to maintain a sensitivity and an alertness, a "queer listening" (Bonenfant, 2010; Hadley \& Gumble, 2019), to the difficulties that children in mental health care might have when trying to express themselves to the researcher in a way that is clearly understood.

It is of special importance to be aware of modalities other than words when interacting with children in efforts to avoid epistemic injustice. It also seems to be crucial to go beyond one's own shortcomings and involve public expressions of the epistemic limitations one has. Knowledge about how epistemic injustice exists in relation to children and patients in mental health care, and how to avoid it, gives us an awareness about why it is important to include children in mental health care and their knowledge in research and to explore the different complex challenges. 


\section{About the author}

Guro Parr Klyve is a music therapist working at the Department of Child and Adolescent Psychiatry, Division of Mental Health at Haukeland University Hospital in Bergen. Guro is currently doing a Ph.D. at The Grieg Academy - Department of Music at the University of Bergen in Norway. The Ph.D.-project is a qualitative study where the purpose is to gain more knowledge about how children experience music therapy during hospital admission in mental health care. Guro uses she/her/hers pronouns and define herself as a white cisgender heterosexual nondisabled woman.

\section{Notes}

1. Throughout this text, I use they/them/their pronouns instead of only his/her in efforts to include those who do not use binary pronouns.

\section{References}

Anderson, E. (2017). Feminist Epistemology and Philosophy of Science. The Stanford Encyclopedia of Philosophy, Retrieved from https://plato.stanford.edu/archives/spr2017/ entries/feminism-epistemology/.

Bain, C. L., Grzanka, P. R., \& Crowe, B. J. (2016). Toward a Queer Music Therapy: The Implications of Queer Theory for Radically Inclusive Music Therapy. The Arts in Psychotherapy, 50, 22-33.

Beresford, P., Nettle, M., \& Perring, R. (2010). Towards a Social Model of Madness and Distress? Exploring What Service Users Say. York, GBR: Joseph Rowntree Foundation.

Bonenfant, Y. (2010). Queer Listening to Queer Vocal Timbres. Performance Research, 15(3), 74-80.

Brownmiller, S. (1990). In Our Time: Memoir of A Revolution. New York: Dial Press.

Butler, J. (2006). Gender Trouble. Feminism and the Subversion of Identity [ProQuest Ebook Central]. Routledge. https://ebookcentral.proquest.com/lib/bergen-ebooks/ detail.action? docID $=710077$.

Carela, H., \& Györffyb, G. (2014). Seen but Not Heard: Children and Epistemic Injustice. The Lancet, 384(9950), 1256-1257.

Einarsdóttir, J. (2007). Research with Children: Methodological and Ethical Challenges. European Early Childhood Education Research Journal, 15(2), 197-211.

Fricker, M. (2003). Epistemic Injustice and a Role for Virtue in The Politics of Knowing. Metaphilosophy, 34(1/2), 154-173.

Fricker, M. (2007). Epistemic Injustice: Power and the Ethics of Knowing. Oxford, GBR: Oxford University Press.

Gilbert, M. A. (2009). Defeating Bigenderism: Changing Gender Assumptions in the Twentyfirst Century. Hypatia, 24(3), 93-112.

Grover, S. (2004). Why won't they Listen to Us? On Giving Power and Voice to Children Participating in Social Research. Childhood, 11(1), 81-93.

Hadley, S., \& Gumble, M. (2019). Beyond the Binaries. Negotiating Gender and Sex in Music Therapy. In S. Hogan (Ed.), Gender and Difference in the Arts Therapies: Inscribed on the Body (pp. 218-228). New York, NY: Routledge.

Hall, K. Q. (2017). Queer Epistemology and Epistemic Injustice. In I. J. Kidd, J. Medina, \& J. G. Pohlhaus (Eds.), The Routledge handbook of epistemic injustice (pp. 158-166). New York, NY: Routledge.

Haraway, D. (1988). Situated Knowledges: The Science Question in Feminism and the Privilege of Partial. Feminist Studies, 14(3), 575-599.

Johnstone, M. J. (2001). Stigma, Social Justice and the Rights of the Mentally Ill: Challenging the Status Quo. Australian and New Zealand Journal of Mental Health Nursing, 10, 200-209. 
Jones, O. (2001). 'Before the Dark of Reason': Some Ethical and Epistemological Considerations on the Otherness of Children. Ethics, Place \& Environment, 4(2), 173-178.

Lakeman, R. (2010). Epistemic Injustice and the Mental Health Service User. International Journal of Mental Health Nursing, 19, 151-153.

Mason, R. (2011). Two Kinds of Unknowing. Hypatia, 26(2), 294-307.

Mills, C. (1997). The Racial Contract. Ithaca, NY: Cornell University Press.

Minghella, A. (2000). The Talented Mr. Ripley [Screenplay]. UK: Paramount Pictures.

Murris, K. (2013). The Epistemic Challenge of Hearing Child`s voice. Studies in Philosophy and Education, 32, 245-259.

Pohlhaus, G. (2012). Relational Knowing and Epistemic Injustice: Toward a theory of willful hermeneutical ignorance. Hypatia: Journal of Feminist Philosophy, 27(4), 715-735.

Powell, M. A., \& Smith, A. B. (2009). Children's Participation Rights in Research. Childhood, 16(1), 124-142.

Rolvsjord, R. (2014). The Competent Client and the Complexity of Dis-ability. Voices: A World Forum for Music Therapy, 14(3), https://doi.org/10.15845/voices.v14i3.787.

Shklar, J. (1990). The Faces of Injustice. London, GBR: Yale University Press.

Sinclair, R. (2004). Participation in Practice: Making it Meaningful, Effective and Sustainable. Children \& Society, 18, 106-118.

Trevarthen, C. (1993). The Self Born in Intersubjectivity: The Psychology of an Infant Communicating. In U. Neisser (Ed.), The Perceived Self: Ecological and Interpersonal Sources of Self-knowledge (pp. 121-173). Cambridge, GBR: Cambridge University Press.

Trevarthen, C., \& Malloch , S. (2000). The Dance of Wellbeing: Defining the Musical Therapeutic Effect. Nordic Journal of Music Therapy, 9(2), 3-17.

UN Committee on the Rights of the Child (CRC). (2005). CRC General Comment No. 7 Implementing Child Rights in Early Childhood, 20 September 2006. Retrieved from https://www.refworld.org/docid/460bc5a62.html.

Wardrope, A. (2015). Medicalization and Epistemic Injustice. Medicine, Health Care and Philosophy, 18, 341-352.

White, E. (1983). A Boy`s Own Story. London: Picador. 